\title{
In vitro studies of inhibitory activity of plant extracts and cow urine on mycelial growth of stem rot, Sclerotim oryzae of rice
}

\author{
Nishant Prakash* and A.P. Sinha \\ Centre of Advanced Studies in Plant Pathology, G.B. Pant University of Agriculture \& Technology, Pantnagar \\ (Uttarakhand), INDIA \\ *Corresponding author. E-mail: gladiator.nishant@gmail.com \\ Received: August 2, 2015; Revised received: July 29, 2016; Accepted: January 3, 2017
}

\begin{abstract}
Soil borne phytopathogen Sclerotium oryzae significantly affect rice production. To reduce load of chemical pesticides, antifungal activity of plant extracts and cow urine against mycelial growth of S.oryzae were tested using poisoned food technique under in vitro condition. Plant extracts of $2.5 \%, 5.0 \%, 7.5 \%$ and $10 \%$ concentration was prepared from Allium cepa, Azadirachta indica, A. sativum, Ricinus communis and Syzygium cumini. Inhibition of mycelial growth of S.oryzae was recorded only in case of A. sativum and A. cepa while Azadirachta indica, Ricinus communis and Syzygium cumini did not show any inhibition of mycelial growth as compared to control. A.sativum plant extracts showed maximum inhibition of mycelia growth of $68.88 \%$ at concentration $10 \%$ followed by $32.96 \%, 22.96 \%$ and $18.88 \%$ at concentration $7.5 \%, 5.0 \%$ and $2.5 \%$ resepectively. $22.60 \%, 19.62 \%, 17.77 \%$ and $8.88 \%$ inhibition of mycelial growth as compared to control was recorded at $10 \%, 7.5 \%, 5.0 \%$ and $2.5 \%$ concentration of plant extracts of A.cepa All the concentration of cow urine inhibited the mycelial growth of $S$. oryzae. Cow urine at the concentration $5,7.5$ and 10.0 per cent resulted in 100 per cent inhibition of mycelia growth of test pathogen as compared to control. Maximum inhibition of 98.14 per cent was observed at 2.5 per cent concentration followed by 1.25 per cent $(63.7 \%)$ concentration. This study showed that A.sativum and A.cepa and cow urine possess antifungal activity under in vitro condition. It can also be tested for antifungal activity under in vivo condition.
\end{abstract}

Keywords: Cow urine, Plant extracts, Sclerotium oryzae

\section{INTRODUCTION}

Stem rot caused by $S$. oryzae Catt. (Magnaporthe salvinii (Catt.) Krause and Webster) is one of the major diseases of rice in India. In India it causes $30-80 \%$ yield loss (Rice Knowledge Management Portal (rkmp), 2011). The use of synthetic fungicides to control disease pose various problems such as residue in feed and food, pathogen resistance (Deising et al., 2008), toxicity to non-target organisms, environmental pollution (Arcury and Quandt, 2003). Hence it has become necessary to use eco-friendly formulations which can fit into integrated pest management.

Various plant products like plant extracts, essential oils, gum, resins etc. were shown to exert biological activity in vitro and in vivo and are used as bio-fungicidal compounds (Pawar and Thaker, 2006; El-Mougy and Alhabeb 2009; Fawzi et al., 2009, Sealey et al. 2007 and Satish et al., 2007). Basak and Lee (2001b, 2002a, 2002b) observed that cow dung and cow urine were capable of suppressing conidial germination and mycelial growth of $F$. oxysporum f.sp. cucumerinum (causing Fusarium wilt of crop). Plant extracts and Cow urine have inhibitory effect on Rhizoctonia spp. (Aye and Matsumoto, 2011; Tiwari and Das, 2011; Al askar and Rashad, 2010;
Seema et al., 2011), S. rolfsii (Amin et al., 2013), S. hydrophyllum (Aye and Matsumoto, 2011), Sclerotinia sclerotiorum (Basak et al., 2002a), Colletotrichum capsici (Rahman et al., 2011 and Kekuda et al., 2014) and Bipolaris sorokiniana (Akhter et al., 2006). Seed borne pathogens like Alternaria alternata, F. oxysporium, Colletotrichum capsici and Curvularia lunata, are also suppressed by Cow dung and cow urine (Sharma et al., 2010). Post harvest pathogens (Mogle, 2013) and plant pathogenic bacteria (Kebede, 2013) are also inhibited by cow urine and plant extracts. Inhibitory effect of cow urine is also observed in case of clinical pathogens (Sathasivam et al., 2010 and Rana and De, 2013) Such compounds, being biodegraded and selective in their toxicity are considered valuable for controlling different plant diseases. The present study was under taken to study the inhibitory effect of plants extracts and cow urine on mycelial growth of $S$. oryzae under in vitro condition.

\section{MATERIALS AND METHODS}

In vitro efficacy of plant extracts against $S$. oryzae: Onion (A. cepa), neem (Azadirachta indica), garlic ( $A$. sativum), castor (Ricinus communis) and Jamun (Syzygium cumini) were used for present investigation. Plant sample were collected from campus area of G.B. 
Pant University of Agriculture and Technology, Pantnagar. Fresh leaves were washed through under tap water followed by sterilized water the leaves were air dried and were grinded with the help of pestle and mortar by taking $(1: 1 \mathrm{w} / \mathrm{v})$ one gram of extract added in $1 \mathrm{ml}$ distilled water separately for each plant extract. The extracts were clarified by passing through two layers of cheese cloth, a Whatman no. 1 filter paper. The extracts were poured in the flasks plugged with cotton and heated at $100^{\circ} \mathrm{C}$ for 10 minutes to avoid contamination (Madavi and Singh, 2005). The sterilized extracts were quoted in the study as 100 per cent extract. The appropriate amount of plant extract was mixed in sterilized distilled water to make the desired concentration $(\mathrm{v} / \mathrm{v})$ for experiments. For bioassay, concentrations of botanicals were prepared by dissolving $1.5,3.0,4.5$ and $6.0 \mathrm{ml}$ of plant extract in $60 \mathrm{ml}$ of sterilized PDA, respectively to get the final concentration of 2.5, 5.0, 7.5 and 10 per cent. In control plate, no plant extracts was mixed.

In vitro bioassay of botanicals: Poisoned food technique (plant extract amended PDA medium) was used to screen different plant extracts in vitro. Different concentrations $(2.5,5.0,7.5,10$ per cent and control) of plant extracts were incorporated to PDA medium for inoculation of the test pathogen in sterilized Petri dishes. The isolated pathogen was grown on PDA medium. Five $\mathrm{mm}$ mycelial disc cut from the margin of actively growing colony was placed at the center of Petri dishes containing different concentration of the poisoned medium and incubated at $28 \pm 1^{\circ} \mathrm{C}$ for 4 days. Radial growth of fungus was measured in millimeter ( $\mathrm{mm})$ after 4 days of inoculation.

In vitro study of the antifungal activity cow urine against $S$. oryzae: Cow urine taken freshly, was filtered with the help Whatman filter paper No. 1 under aseptic conditions in the laminar air flow chamber. The filtrate obtained was then mixed with sterilized water to have the final concentrations viz. $0.625,1.25,2.50$, $5.0,7.510 .0 \%$ and control respectively. These concentrations were ready to be used to check the efficacy of cow urine against $S$. oryzae. In control plate, no cow urine was mixed.

In vitro bioassay of cow urine: Effect of cow urine at different concentrations on the radial growth of the test fungus was evaluated by poisoned food technique on potato dextrose agar (PDA) medium. Different concentrations of cow urine were taken viz. $0.625,1.25,2.50$, 5.0, 7.5 and $10.0 \%$. The desired amount of the cow urine suspension were added in the medium and mixed thoroughly before plating. Different medium toxicated with cow urine was poured in each Petri plate. Subsequently a $5 \mathrm{~mm}$ mycelial disc of 4 days old culture of S. oryzae was cut with sterile cork borer and placed in centre of each Petri plate. The plates were incubated at $27^{\circ} \mathrm{C}$. The diameter of the fungal colony was measured after 4 days of incubation. After 4 days of incubation percent inhibition was calculated by using the following formula:

$$
\text { Percent inhibition }=\frac{X-Y}{x} \quad \times 100
$$

Where,

$\mathrm{X}=$ colony diameter in check,

$\mathrm{Y}=$ colony diameter on amended medium

\section{RESULTS AND DISCUSSION}

Effect of plant extracts on radial growth of S. oryzae: Table 1 shows the effect of certain botanicals at different concentrations on the mycelial growth of $S$. oryzae in in vitro condition. Inhibition of mycelial growth varied significantly with different botanicals and their concentrations. The observations of the experiment were taken 4 days after inoculation. The effect on plant extracts on inhibition of mycelial growth of S.oryzae is presented in table 1. Out of five plant extract (viz., A. cepa, Azadirachta indica, A. sativum, Ricinus communis and Syzygium cumini), $A$. cepa and A. sativum showed inhibitory effect on mycelial growth of S.oryzae. Azadirachta indica, Ricinus communis and Syzygium cumini did not show any inhibitory effect on mycelial growth of S.oyzae. In case of A.cepa at concentration of 2.5, 5.0, 7.5 and 10 per cent, radial growth of mycelium of S.oryzae were $82.00,74.00,72.33$ and $69.66 \mathrm{~mm}$ recorded. In case of A.cepa, per cent inhibition of mycelial growth of S.oryzae of $8.88,17.77,19.62$ and 22.60 per cent respectively, was recorded as compared to control. At concentration of $2.5,5.0,7.5$ and 10 per cent in case of A.sativum, 73.00, 69.33, 60.33 and $28.00 \mathrm{~mm}$ respectively, mycelial growth was recorded. In case of A.sativum,per cent inhibition of mycelial growth of S.oryzae of $18.88,22.96,32.96$ and 68.88 per cent was recorded as compared to control. Per cent inhibition at all concentration were statistically significant from control. Per cent inhibition at each concentration were also statistically significant different from each other. Per cent of mycelial growth is more in A. sativum than A.cepa. Seema et al.(2011) reported that out of 10 plant extracts viz., Thevetia peruviana, Ocimum basilicum, Piper betel, Murraya koenigii, Chrysanthemum coronarium, Polyalthia longifolia, Catharanthus roseus, Pelargonium graveolens, Moringa officinalis and Lawsonia inermis, plant extracts of only four plant (Lawsonia inermis, Piper betel, Polyalthia longifolia and Pelargonium graveolens) showed antifungal activity against R.solani (infecting Tobacco). Seema et al. (2011) also reported that with the increase in concentration of plant extracts inhibition of mycelial growth also increases. As in present investigation also, out of five plant (A. cepa, Azadirachta indica, A. sativum, Ricinus communis and Syzygium cumini), plant extracts of only two plant viz., A. cepa and A. sativum showed inhibitory effect on mycelial growth of S.oryzae. In case of Allium cepa and Allium sativum, 
Table 1. Effect of plant extracts on radial growth of $S$. oryzae on PDA at $28 \pm 1{ }^{\circ} \mathrm{C}$.

\begin{tabular}{|c|c|c|c|c|c|c|c|c|c|}
\hline \multirow{3}{*}{ Plant extracts } & \multicolumn{9}{|c|}{ Concentrations (\%) } \\
\hline & \multicolumn{5}{|c|}{ Radial growth* $(\mathrm{mm})$} & \multicolumn{4}{|c|}{ Per cent inhibition } \\
\hline & 2.5 & 5.0 & 7.5 & 10.0 & Mean & 2.5 & 5.0 & 7.5 & 10.0 \\
\hline Allium cepa & 82.00 & 74.00 & 72.33 & 69.66 & 74.50 & 8.88 & 17.77 & 19.62 & 22.60 \\
\hline Azadirachta indica & 90.00 & 90.00 & 90.00 & 90.00 & 90.00 & 00.00 & 00.00 & 00.00 & 00.00 \\
\hline Allium sativum & 73.00 & 69.33 & 60.33 & 28.00 & 57.66 & 18.88 & 22.96 & 32.96 & 68.88 \\
\hline Ricinus communis & 90.00 & 90.00 & 90.00 & 90.00 & 90.00 & 00.00 & 00.00 & 00.00 & 00.00 \\
\hline Syzygium cumini & 90.00 & 90.00 & 90.00 & 90.00 & 90.00 & 00.00 & 00.00 & 00.00 & 00.00 \\
\hline Control & 90.00 & 90.00 & 90.00 & 90.00 & 90.00 & 00.00 & 00.00 & 00.00 & 00.00 \\
\hline Mean & 85.83 & 83.88 & 82.11 & 76.27 & 82.02 & & & & \\
\hline \multirow[t]{3}{*}{$\mathrm{CD}$ at $5 \%$} & $\mathrm{~A}($ dose $)$ & $=1.79$ & & & & & & & \\
\hline & B (treatn & $n t)=2.19$ & & & & & & & \\
\hline & $\mathrm{A} \times \mathrm{B}$ & $=4.39$ & & & & & & & \\
\hline
\end{tabular}

with the increase in concentration of plant extracts, inhibiton of mycelial growth increases. Onion broth (Plant extracts of A.cepa) successfully control seedlings damping off caused by R.solani and S. rolfsii (Rivera, 2013). Plant extracts of A.sativum (Garlic) showed inhibitory affect on broad range of soil borne of plant pathogen (viz., Pythium aphanidermatum, P. irregulare, P. ultimum, Phytophthora cinnomomi, Phytophthora nicotianae, $R$. solani, F. oxysporum, and Thielaviopsis basicoli). (Sealy et al., 2007). Hence these findings of A.cepa and A.sativum is in support of findings of this investigation. Amin et al. (2013) found that among different plant extracts (rhizome of turmeric, rhizome ginger, neem leaf, tobacco leaf, tobacco leaf extract in water, tobacco leaf extract in cow's urine,), Plant extracts of neem (A.indica) showed least inhibition of mycelial growth and sclerotia formation in case of $S$. rolfsi. The findings about A.indica is similar with Amin et al. (2013). While A.indica plant extracts also have inhibitory affect on conidial germinaton and germ tube formation of Colletotrichum capsici (Rahman, 2011). It also has inhibitory affect on soil borne rice phytopathogens Rhizoctonia spp and S. hydrophyllum (Aye and Matsumoto, 2011). A.indica plant extracts in combination with cow dung has 100 per cent inhibitory affect on conidial germination of Bipolaris sorokiniana (Akhter et al., 2006). This report of A.indica is contradictory with the present finding where A.indica did not show any inhibitory affect on mycelia growth of S.oryzae. Aqueous extract of Syzygium cumini showed inhibitory affect on seed borne Aspergillus spp. (Satish et al., 2007). This finding is also contradictory with the present findings.

Effect of cow urine on the radial growth of S. oryzae: Inhibition of mycelial growth varied significantly with different concentrations of cow urine. The observations of the experiment were taken 3 days after inoculation. Data graphical representation regarding antifungal activity of cow urine against test fungus are presented in table 2. At concentration 2.5, 1.5 and 0.62 per cent, radial growth of mycelium of $S$. oryza was $1.66,32.66$ and $50.33 \mathrm{~mm}$ recorded respectively. No mycelial growth was recorded at the concentrations of
Table 2. Effect of Cow urine on radial growth of $S$. oryzae on PDA at $28 \pm 1^{\circ} \mathrm{C}$.

\begin{tabular}{lcc}
\hline $\begin{array}{l}\text { Cow urine Concen- } \\
\text { trations (\%) }\end{array}$ & $\begin{array}{c}\text { Radial growth } \\
(\mathbf{m m})\end{array}$ & $\begin{array}{c}\text { Per cent } \\
\text { inhibition }\end{array}$ \\
\hline 0.625 & 50.33 & 44.07 \\
1.25 & 32.66 & 63.70 \\
2.50 & 1.66 & 98.14 \\
5.00 & 0.00 & 100.00 \\
7.50 & 0.00 & 100.00 \\
10.00 & 0.00 & 100.00 \\
Control & 90.00 & 0.00 \\
CD at 5\% & & 9.92 \\
\hline
\end{tabular}

5.0, 7.5 and 10.0 per cent. Cow urine at the concentrations of 5.0, 7.5 and 10.0 per cent were found highly effective against $S$. oryzae, whereas, cow urine at the concentrations of $2.5,1.5$ and 0.62 per cent resulted in 98.0, 63.7 and 44.07 per cent inhibition, respectively. Per cent inhibiton at the concentration of 2.5, 1.5 and 0.62 per cent are statistically significantly different from control as well as they are also significantly different from each other. Per cent inhibition at concentration 2.5, 5.0, 7.5 and 10.0 per cent are statistically at par with each other. Per cent inhibition of mycelial growth is more in cow urine as compared to $A$. cepa and A. sativum.

Cow urine and cow dung has inhibitory affect on mycelial growth and suppressive affect on sclerotial germination of Sclerotinia sclrotiorum (Basak et al., 2002a) and F. solani fsp. cucurbitae (Basak et al., $2002 b$ ). In case of $F$. latinerum causing Fusarium bark disease of coffee, conidial germination, germ tube length, mycelial growth rate and sporulation are suppressed by cow urine (Gotora et al., 2014). 40, 50, 60 and 70 per cent concentration of cow urine suppress sclerotial germination and mycelial growth of S.rolfsii causing foot and root rot of Betel Vine (Amin et al., 2013). Conidial germination of Alternaria alternata, $F$. oxysporium, Colletotrichum capsici and Curvularia lunata (Sharma et al., 2010) as well as Bipolaris sorokiniana (Akhter et al., 2006) is suppressed by cow urine and cow dung. Plant extracts prepared from cow urine has more antifungal activity. Cow urine based plant extracts has more inhibitory affect on bell pepper 
pathogens ( $R$. solani, Sclerotinia sclerotiorum, $S$. rolfsii, Phytophthora nicotianae, $F$. oxysporum f. sp. capsici, F. solani and Colletotrichum capsici.) (Ashlesha et al., 2013), anthracnose of chilli (Colletotrichum capsici) (Kekuda et al., 2014) and sheath blight of rice ( $R$. solani) (Tiwari and Das, 2011). Apart from this, cow urine also has antimicrobial affect on clinical pathogens like Bacillus subtilis, Bacillus cereus, Staphylococcus aureus, Staphylococcus epidermidis, Escherichia coli, Enterobacter aerogenes, Klebsiella pneumoniae, Pseudomonas aeruginosa, Proteus vulgaris, Salmonella typhi and two molds-Aspergillus flavus and Candida albicans ( Rana and De, 2013; and Sathasivam et al., 2010). All these reports of cow urine is in congruency with the findings of present investigation.

\section{Conclusion}

Out of five plant extracts of Allium cepa, Azadirachta indica, Allium sativum, Ricinus communis and Syzygium cumini, only $A$. cepa and $A$. sativum showed inhibitory effect on mycelial growth of S.oryzae. Plant extracts of $A$. indica, $R$. communis and S. cumini did not have inhibitory affect on S.oryzae but these plant extracts may have antifungal activity against other plant pathogens like $S$. rolfsi (causing foot and root rot of betel vine), Colletotrichum capsici (causing anthracnose of chilli) soil borne rice phytopathogens Rhizoctonia spp and S. hydrophyllum and on conidial germination of Bipolaris sorokiniana. Cow urine was inhibitory to mycelial growth of S.oryzae at all concentrations. At high concentration of cow urine, no mycelial growth was recorded. Hence this investigation clearly showed antifungal potential of $A$. серa and A. sativum and cow urine against S.oryzae. Antifungal potential was highest in cow urine followed by A. sativum and A. cepa.

\section{REFERENCES}

Al-Askar, A. A. and Rashad, Y. M. (2010). Efficacy of some plant extracts against Rhizoctonia solani on pea. Journal of Plant Protection Research, 50 (3): 239-243

Amin, R., Sarker, B. C., Adhikary, S. K., Sultana, S. and Zubair, T. (2013). Effect of some botanical extracts and cow's urine on Sclerotium rolfsii causal agent of foot and root rot of betel vine. The International Journal of Engineering And Science, 2(9): 77-82

Arcury, T.A. and Quandt, S.A. (2003). Pesticides at work and at home: exposure of migrant farmworkers. Lancet, 362 (9400): 2021

Ashlesha, A., Thakur, S., Paul, Y. S., Rameshwar and Payal (2013). Antifungal activity of distillates of cow urine and botanicals. Plant Disease Research, 26 (2): 163164

Aye, S. S. and Matsumoto, M. (2011). Effect of some plant extracts on Rhizoctonia spp. and Sclerotium hydrophilum. Journal of Medicinal Plants Research, 5(16): 3751 $-3757$
Basak, A. B. and Lee, M. W. (2001b). Comparative efficacy and in vitro activity of cow urine and cow dung for controlling Fusarium wilt of cucumber. Abstract published in the 2001 Korean Society of Plant Pathology annual meeting and International conference, held on 25 $-30^{\text {th }}$ October, 2001, Kyongju TEMF hotel, Korea, pp.49.

Basak, A. B., Lee, M. W. and Lee, T.S. (2002b). Inhibitive Activity of Cow Urine and Cow Dung to $F$. solani $f_{s p}$ cucurbitae. Mycobiology, 30(1): 51-54

Basak, A. B., Lee, M. W. and Lee, T.S. (2002a). Inhibitive Activity of Cow Urine and Cow Dung against Sclerotinia sclerotiorum of Cucumber. Mycobiology, 30(3): 175-179

Deising, H.B., Reimann, S. and Pascholati, S.F. (2008). Mechanisms and significance of fungicide resistance. Braz. J. Microbiol, 39 (2): 286-295

El-Mougy, N.S. and Alhabeb, R.S. (2009). Inhibitory effects of pow-dered caraway and peppermint extracts on pea root rot under greenhouse conditions. J. Plant Protection Res., 49 (1): 93-96

Fawzi, E.M., Khalil, A.A. and Afifi, A.F. (2009). Antifungal effect of some plant extracts on Alternaria alternata and Fusarium oxyspo-rum. Afr. J. Biotechnol. 8 (11): 2590 2597

Gotora, T., Masaka, L. and Sungirai, M. (2014). Effect of Cow Urine on the Growth Characteristics of Fusarium lateritium, an Important Coffee Fungus in Zimbabwe. International Journal of Agronomy, 1-4

Kebede, M., Ayalew, A. and Yesuf, M. (2013). Efficacy of plant extracts, traditional materials and antibacterial chemicals against Xanthomonas campestris pv. vesicatoria on tomato seed. 7(20):2395-2400

Kekuda, T.R.P., Nishanth, B.C., Kumar, S.V.P., Kamal, D., Sandeep, M. and Megharaj, H.K.. (2014). Cow urine concentrate: a potent agent with antimicrobial and anthelmintic activity. Journal of Pharmacy Research, 3 (5): 1025-1027

Rivera, M.C., Wright, E.R., Fabrizio, M.C., Freixa, G., Cabalini, R. and Lopez, S.E. (2013). Control of seedling damping off caused by Rhizoctonia solani and Sclerotium rolfsii using onion broths. International Journal of Experimental Botany, 82: 227-234

Madavi, S. and Singh, R.P. (2005). Management of mushroom pathogens through botanicals. Indian PhytoPath. 58: $189-193$

Mogle, U.P. (2013). Effect of medicinal plant extracts against the post harvest fungal pathogens of cowpea legumes. Trends Life Sci., 2 (4): 22-27

Akhter, N., Vivek, M.N., Manasa, M., Kambar, Y., Noor Nawaz, A. S. and Raghavendra, H. L. (2006). Inhibitory effect of different plant extracts, cowdung and cowurine on conidial germination of Bipolaris sorokiniana. Journal of Biosciences, 14: 87-92

Pawar, V.C., Thaker, V.S. (2006). In vitro efficacy of 75 essential oils against Aspergillus niger. Mycoses, 49(4): 316-323

Rana, R. and De, S. (2013). In vitro antimicrobial screening of cow urine-a potential natural antimicrobial agent. International Journal of Bioassays, 2(2): 436-439

Rahman, M.A., Rahman, M. M., Azad, A.K. and Alam, M.F. (2011). Inhibitory effect of different plant extracts and antifungal metabolites of Trichoderma strains on the 
conidial germination and germ tube growth of Colletotrichum capsici causing chili anthracnose. International Journal of Agronomy and Agricultural Research, (1): 20-28

Sathasivam, A., Muthuselvam, M., and Rajendran, R. (2010). Antimicrobial activities of cow urine distillate against some clinical pathogens. Global Journal of Pharmacology, 4(1): 41-44

Satish, S., Mohana, D.C., Ranhavendra, M.P. and Raveesha, K.A. (2007). Antifungal activity of some plant extracts against important seed borne pathogens of Aspergillus sp., 3(1): 109-119

Sealy, R., Evans, M.R. and Rothrock, C. (2007). The Effect of a Garlic Extract and Root Substrate on Soilborne
Fungal Pathogens. Hortechnology, 17(2):169-173

Seema, M., Sreenivas, S.S., Rekha, N.D. and Devaki, N.S. (2011). In vitro studies of some plant extracts against Rhizoctonia solani Kuhn infecting FCV tobacco in Karnataka Light Soil, Karnataka, India. Journal of Agricultural Technology, 7 (5): 1321-1329

Sharma, R., Sharma, A. and Agarwal, A. K. (2010). Impact of cow urine and composted cow dung on the incidence of seed borne Phytopathogenic fungi. International Journal of Plant Sciences, 5(2): 579-581

Tiwari, R.K.S. and Das, K. (2011). Inhibitory effect of cow urine based plant extracts against Rhizoctonia solani causing sheath blight of rice. Indian Phytopath, 64 (3): 265-268 